\title{
References
}

Arece J, Mahieu M, Archimède H, Aumont G, Fernández M, González E, Cáceres 0 and Menéndez-Buxadera A 2004. Comparative efficacy of six anthelmintics for the control of nematodes in sheep in Matanzas, Cuba. Small Ruminant Research 5, 61-67.

Papadopoulos E 2008. Anthelmintic resistance in sheep nematodes. Small Ruminant Research 76, 99-103.

\section{Trypanotolerant and trypanosusceptible type dual purpose cattle in the lownlands of Venezuela: phenotypic identification and characterization}

\author{
Rita Tamasaukas ${ }^{\dagger}$ \\ LABIPRESAN-UNERG, Venezuela \\ Introduction
}

A sustainable strategy for the control of trypanosomosis is to select bovines according to their tolerance to challenges by $T$. vivax, a quality trait widely studied in the African continent, using diverse methods: identification by hematological values, modulation to infection, studies of molecular genetics, among others.

\section{Materials and methods}

The present field study was carried out in order to identify cattle and characterize them as Trypanotolerant (TT) and Trypanosusceptible (TS) animals to $T$. vivax based on phenotypic markers: clinical, parasitological, hematological, serological and immunological evaluations; as well the association with average body score of animals determined by morphometric variables.

\section{Results}

By evaluating 790 bovines (females with two or more calvings and males selected randomly) from 20 herds located at Apure, Aragua, Barinas, Cojedes and Guárico states, we identified three animal types according to their size: small (41.58\%), medium (26.67\%) and large (29.75\%), We identified 85.57\% (84/98) TT and 14.3\% (14/98) TS animals. According to their size, $45.91 \%$ were TT and $7.14 \%$ TS for small and medium size, while $11.2 \%$ TT and $2.04 \%$ TS were registered for large size. Prevalence values of $T$. vivax were $0.83 \%$ Apure, $8.47 \%$ Aragua, $16.66 \%$ Barinas, $17.5 \%$ Cojedes and $24.03 \%$ Guárico, with a significant difference between states $(P<0.05)$. A hematocrit mean value of $31.48 \%$ (range of 22.66 to $36.23 \%$ ) was obtained with a significant association $(P<0.05)$ between ocular conjunctive color and the Hto \%. Hemoglobin values (35.82\%) were equal or below $10 \mathrm{~g} \mathrm{dL}^{-1}$. There was no significant association between the presence of T. vivax and Hto values (acceptable). A $85.76 \%$ seroprevalence by Ac-Elisa Test was obtained and $62.61 \%$ were positive to immune complexes.

\section{Conclusions}

The results show the effectiveness of the criteria used in this study to determine Trypanotolerant and Trypanosusceptible type cattle for the first time in Venezuela and America. This may be a useful tool to identify tolerant animals to one of the major illnesses in the region and can be used as a complementary element to selection and breeding programs among farmers or public and private institutions.

\section{Acknowledgements}

The authors gratefully acknowledge funding from: subproyecto de Biotecnología BID FONACIT II INIA No.2005000008; INIA Guárico subproyecto de Mantenimiento de las Unidades de Producción Animal del INIA Guárico código NT-APU-05-001-06 and Proyecto PEM FONACIT-UNERG/IDESSA/LABIPRESAN No. 2001001620.

\footnotetext{
${ }^{\dagger}$ E-mail: tamasaukas.rita@gmail.com
} 